рассматривалась позиция выбранных признаков в таком списке. Видно, что для всех классов наибольшие вероятности имеют признаки, не дающие конкретной информации о принадлежности твита к определенному классу, а просто слова, наиболее часто встречающиеся в текстах твита [5].

Таким образом, умению заинтересованности информацией необходимо учить студентов в течение всех лет обучения в вузе при подготовке к практическим занятиям, докладам, рефератам, конференциям и т.д. Формирование навыков заинтересованности к предоставляемой информации, построение изложения информации масс-медиа необходимость для современного специалиста, нуждающегося в подобных умениях. Обучение в таком формате вырабатывает навыки получения необходимой информации из многообразия источников, стимулированию деловой активности и увеличению профессиональной мобильности. Приводит к повышению навыков выступления перед аудиторией, структурированному изложению предоставляемой информации, умению заинтересовать аудиторию, что несомненно должно вести к профессиональному росту самого специалиста.

1. Асеев, В.Г. Мотивация учебной деятельности и формирование личности / В.Г. Асеев. - М.: Просвещение, 2006. - 267 с.

2. Головаха, Е.И. Жизненная перспектива и профессиональное самоопределение молодежи / Е.И. Головаха. - Киев: Изд-во Наукова думка, 2008. - 310с.

3. Ермолаева, Е.П. Социальные функции и стратегии реализации профессионализма в системе «человек - профессия - Общество» / Е.П. Ермолаева // Психологический журнал. - 2005. - №4. C. 30-40.

4. Рубцова Ю.В. Метод построения и анализа корпуса коротких текстов для задачи классификации отзывов // Электронные библиотеки: перспективные методы и технологии, электронные коллекции: Труды XV Всероссийской научной конференции RCDL'2013. Ярославль. 2013. С. 269275.

5. Четверкин И. И., Лукашевич Н. В. Тестирование систем анализа тональности на семинаре РОМИП-2012 // Т. 2: Доклады специальных секций РОМИП - М.: Изд-во РГГУ, 2013.

\title{
Горбунова Ж.О., Зародыш Е.С. Адаптация к дистанционному обучению студентов первого курса СГУПСа в период пандемии
}

ФГБОУ ВО СГУПС

doi: $10.18411 / \mathrm{j}-05-2021-224$

(Россия, Новосибирск)

Научный руководитель

Негода И.Г.

\section{Аннотация}

В статье рассматривается проблема адаптации к дистанционному обучению студентов первого курса СГУПСа в период пандемии. В момент адаптации у студентов происходит смена деятельности, появляется новое окружение, их внутренние установки претерпевают сильные изменения. Цель статьи - определить уровень адаптации студентов СГУПСа к дистанционному обучению в период пандемии. В ходе работы был проведен массовый опрос и анализ документов. Учитывались ответы студентов факультета «Управление персоналом».Итоги работы позволили выявить некую закономерность, которая может заинтересовать методических работников ВУЗов.

Ключевые слова: адаптация, дистанционное обучение, СГУПС.

\section{Abstract}

The article deals with the problem of adaptation to distance learning of first-year students of the STU during the pandemic. At the moment of adaptation, students change their 
activities, a new environment appears, and their internal attitudes undergo strong changes. The purpose of the article is to determine the level of adaptation of STU students to distance learning during the pandemic. In the course of the work, a mass survey and analysis of documents were conducted. The answers of students of the Faculty of "Personnel Management"were taken into account. The results of the work allowed us to identify a certain pattern that may be of interest to methodological staff of universities.

Keywords: adaptation, distance learning, STU.

Каждый год, как и все учебные заведения, наш ВУЗ гостеприимно распахивает двери для пополнения большого и дружного коллектива студентов, которые поступают из разных школ и становятся первокурсниками нашего учебного заведения.

Но пандемия стала глобальным вызовом для систем высшего образования во всём мире.

Студенческая жизнь начинается с первого курса и, поэтому успешная адаптация первокурсника к жизни и учебе в ВУЗе является залогом дальнейшего развития каждого студента как человека, будущего специалиста.

В последнее время в СГУПСе организован такой вид обучения как дистанционное. Дистанционное образование - одна из образовательных областей, которая предполагает обучение с использованием информационных технологий. Появляются новые средства обучения, учебные интерфейсные модули, аудио - видео средства. При этом многие факторы, значимые для системы традиционного очного обучения, остаются не менее значимыми и для системы дистанционного образования.

Система дистанционного образования только в том случае станет отвечать своему назначению, если в ней будет заложен ряд факторов: наличие системы адаптации учащихся и студентов к использованию информационных технологий; наличие достаточно устойчивого и эффективного управления учебной деятельностью, a, следовательно, и выбором оптимальной стратегии обучения. Поэтому тема адаптации студентов к использованию информационных технологий в дистанционном образовании в период пандемии является актуальной на сегодняшний день.

Цель исследования: определить уровень адаптации студентов СГУПСа факультета «Управление персоналом» к дистанционному обучению в период пандемии.

Задачи исследования:

1. Изучить понятие адаптация;

2. Проанализировать опрос студентов 1 курса УП (метод анкетирования);

3. Сравнить результаты сессий 2019/2020гг. и 2020/2021гг. на основе документов (метод анализа документов);

4. Сопоставить итоги двух методов

5. Сделать вывод об уровне адаптации студентов и разработать рекомендации по ее усовершенствованию.

В момент адаптации у студентов происходит кардинальная смена деятельности и окружения, их внутренние установки претерпевают сильные изменения. Происходит переориентация ценностей, освоение новых социальных ролей, студенты по - другому начинают воспринимать себя и других. Успешная адаптация первокурсника к жизни в ВУЗе является залогом дальнейшего развития каждого студента как личности и как будущего специалиста.

Для раскрытия проблемы адаптации студентов УП к обучению проанализируем понятие «адаптация» в различных аспектах.

Социальный аспект предполагает рассмотрение адаптации учащихся и студентов как процесса. Адаптация к обучению достигается мотивационной перестройкой личности. Процесс адаптации неразрывно связан с повышением 
активности личности, с формированием новых личностных качеств, таким образом, обучение на начальном этапе в новой ситуации - это адаптационный процесс.

Технологический аспект имеет двоякое назначение, с одной стороны адаптация это составляющая часть технологии обучения, с другой стороны - это процесс освоения технических ресурсов (аудио, видео, средств вычислительной техники и других), используемых как для самой адаптации, так и для дальнейшего обучения.

Адаптация как процесс к любому виду деятельности, в том числе и к обучению, обеспечивает вживание в коллектив, приобщение к этой деятельности, к режиму работы и обучения, обязанностям, особенностям рабочего или учебного места, стилю и отношениям в новом коллективе и другим особенностям. Адаптация при этом обеспечивает успешность деятельности человека в пределах существующих условий, требований, норм без ущерба для здоровья и личных и общественно-значимых устремлений. Успешность и сроки адаптации учащихся и студентов зависят от уровня предыдущей социальной и профессиональной готовности к какой либо, в частности, к учебной деятельности в конкретных условиях.

При этом адаптация - процесс не только приспособления, но и взаимодействия среды и человека. Приспособление - это первичная адаптация. Адаптироваться - значит прийти к соответствию, к адекватному взаимодействию со всеми элементами данной системы. Адаптировать - значит взаимодействовать в направлении приведения данной системы в адаптивное соответствие с системой более высокого уровня организации, задачи которой общественно значимы, масштабней. Под данной системой будем понимать всевозможные типы личностной организации обучаемого, набор привычных стилей общения и обучения. Под системой более высокого уровня будем понимать обучающую ситуацию, новые или изучаемые далее предметы, новый коллектив учителей и учащихся, преподавателей и студентов. Различение типов личностной организации деятельности человека представляется целесообразным, т.к. позволяет рассмотреть процессы адаптации в их соотношении с социальной активностью личности.

Для реализации нашего исследования мы разработали анкету, используя Google Forms. Была создана веб-страница с вопросами, которая распространялась через электронную почту и социальную сеть «ВКонтакте». В исследовании приняли участие 126 студентов СГУПС факультета «Управление персоналом».

Мы просили определить студентов как они адаптировались к дистанционному обучению в период пандемии и какие трудности у них возникли.

Анализ данных позволяет утверждать, что студенты хорошо адаптировались к дистанционному обучению и им удобно обучаться в данном режиме.

Уровень мотивации к обучению не изменился, что показывает $61 \%$ ответов студентов. Почти половина 49,2\% студентов удовлетворены процессом обучения в дистанционном режиме. Формат дистанционного обучения студенты не представляют без таких инструментов и программ как Moodle (99.2\%) и ZOOM (84.1\%). При этом отметим, что 42,9\% опрошенных говорят о технических проблемах в работе данных программ. Чаще всего преподаватели размещают учебный материал в Moodle $(72,2 \%)$ и проводят онлайн тестирование $(17,5 \%)$. По мнению студентов преподавательский состав объясняет все предельно понятно и интересно, об этом говорит 49,2\% ответов, но стоит отметить, что $22,2 \%$ студентов не полностью осваивает материал и оценивает работу преподавательского состава как «удовлетворительно». Так же в процессе дистанционного обучения у студентов возник ряд трудностей, таких как сложность выполнения практических заданий без объяснения преподавателей $(53,2 \%)$ и большой объем задаваемых материалов $(44,4 \%)$.Больше всего в дистанционном обучении студентам понравилось гибкость учебного процесса $(69,8 \%)$, а также обучение в комфортной и привычной обстановке $(68,3 \%)$. В этих ответах мы видим еще и устоявшийся ритм познавательной активности студентов, сложившийся режим 
активного выполнения домашних заданий вечером или ночью, проявлялся и в удаленном обучении.

Отметим, что 7,1\% студентов не нашли никакого позитивного аспекта для себя, вероятно, не получив возможности самореализоваться. Мы предполагаем, что в данной группе выделились те студенты, которые не имеют необходимого организационнотехнического обеспечения. Не имеют ни постоянного интернета, ни собственного компьютера, или другого технически продвинутого гаджета. При этом имеют собственный компьютер для обучения $69 \%$ студентов, a $30,2 \%$ учатся преимущественно со смартфона или с общего семейного компьютера.

Подводя итоги анализа опроса, можно сделать вывод, что многие студенты хорошо адаптировались к новому формату обучения и выбрали бы его вместо традиционного. По нашему мнению дистанционное обучение не способствует формированию любви к выбранной профессии, что подтверждают и сами студенты, затрудняясь ответить на данный вопрос.

Для более объективного анализа результатов адаптации помимо анкетирования, мы проанализировали результаты сессий 2019/2020гг и 2020/2021гг и сравнили их.

Для анализа было выбрано 6 групп факультета «Управление персоналом». Итоги исследования показали, что студенты разных направлений по своему адаптировались к дистанционному обучению. В частности, адаптация у студентов таких направлений как «Управление персоналом» и «Психология» прошла отлично, об этом говорит $54,8 \%$ оценок «отлично» в 2020/2021гг. против 43\% в 2019/2020гг. Студенты направления «Государственное и муниципальное управление» также неплохо адаптировались к новому формату обучения, о чём свидетельствует примерно одинаковый процент оценок «удовлетворительно», «хорошо» и «отлично» соответственно. Что касается направления «Реклама и связи с общественностью», то здесь результаты показали, что обучающиеся в меньшей степени адаптировались к дистанционному обучению. Так как оценку «отлично» за четыре предмета получили всего 22 раза вместо 65 в прошлом году, а количество сдавших на «удовлетворительно» увеличилось в 2 раза (23 против 11$)$.

Проведенное анкетирование и анализ документов помогли выявить нам некую закономерность. По анкетированию мы видим, что большинство студентов удовлетворено дистанционной формой обучения, но по анализу документов наблюдается у половины спад знаний.

Подводя итоги, мы хотели бы отметить, что вся система обучения в ближайшем будущем будет трансформироваться, и студентам надо будет принимать эти новые трансформации. Возможно, мы окажемся в ситуации, когда определенная часть занятий будет проходить только on-line, какие-то занятия будут только в дистанционном формате, но что стало очевидным, так это то, что очные занятия студентов будут являться важной и неотъемлемой частью образовательного процесса.

Грищенко Е.Г.

Экологическая компетентность педагога дошкольного образования: сущность, содержание, критерии и уровни сформированности

Белгородский государственный национальньй исследовательский университет (НИУ «БелГУ»)

МБДОУ $/$ /с № 15

doi: 10.18411/lj-05-2021-225

(Россия, Белгород)

Научный руководитель

Шинкарева Л.В.

\section{Аннотация}

В статье поднимается проблема формирования экологической компетентности педагога дошкольного образования. Автор, опираясь на исследования ученых, дает 